\title{
Transisi Pengelolaan Dari Sistem Paratransit Mikrolet Menuju Sistem Transit Bus Feeder
}

\author{
Wahju Herijanto ${ }^{a *}$, Indrasurya B. Mochtar ${ }^{\mathrm{a}}$, Achmad Wicaksono ${ }^{\mathrm{b}}$ \\ ${ }^{a}$ Departemen Teknik Sipil, FTSP, Institut Teknologi Sepuluh Nopember(ITS), Kampus ITS, Sukolilo, Surabaya 60111, Indonesia \\ ${ }^{b}$ Jurusan Teknik Sipil, Fakultas Teknik, Universitas Brawijaya, jl Veteran, Malang 65145 , Indonesia
}

\begin{abstract}
Sistem paratransit yang diterapkan pada 58 rute mikrolet Surabaya saat ini membebankan resiko finansial pada sopir. Hal ini menyebabkan sopir melakukan praktek pengaturan headway tak beraturan. Sistem transit yang akan diterapkan pada 35 rute angkutan bus feeder masa depan di Surabaya mensyaratkan adanya jadwal yang ditaati sehingga diperlukan pengelolaan yang baik, dimana hal ini memerlukan perubahan sistem pengelolaan. Terdapat beberapa sistem pengelolaan transit yang telah diaplikasikan di berbagai kota dunia. Tujuan studi ini adalah memilih sistem pengelolaan agar tercipta penjadwalan yang ditaati, serta pengelolaan pada masa transisi agar sistem berjalan dan yang dirugikan sesedikit mungkin dengan menggunakan analisis multi kriteria. Hasilnya terpilih sistem pengelolaan sistem transit yang tepat untuk angkutan feeder di Surabaya, serta transisinya dari pengelolaan konvensional saat ini.

Keywords: Sistem transit; bus feeder; transisi pengelolaan; resiko finansial; penjadwalan.
\end{abstract}

\section{Pendahuluan}

Surabaya sebagai kota besar dengan penduduk 3 juta jiwa dan 6 juta jiwa populasi metropolitan area telah mempunyai rencana untuk mengganti moda mikrolet yang bersifat paratransit menjadi sistem transit yang dinamakan angkutan feeder. Angkutan feeder ini akan terintegrasi dengan angkutan bus trunk dan angkutan massal cepat (semi rapid transit). Sistem transit yang akan diaplikasikan menuntut persyaratan rute, jadwal dan tarif yang terdefinisi dan terinformasikan.

Meskipun Surabaya telah mempunyai kajian yang meliputi rencana rute angkutan masal cepat, bus trunk dan angkutan feeder serta menyebutkan bahwa akan ada time table, jadwal yang terdefinisi dan terinformasi (fixed schedule) akan sulit dipenuhi apabila sistem pengelolaan tetap seperti saat ini, dimana sopir menyewa kendaraan secara harian dan sopir mencari penumpang. Banyak sedikitnya penumpang akan mempengaruhi penghasilan sopir sehingga sopir berusaha memperoleh penumpang semaksimal mungkin. Yang dipraktekkandi Surabaya adalah memperbesar jarak dengan angkutan umum sebelumnya, seperti berangkat menunggu penumpang penuh, memperlambat kendaraan, dan berhenti lama di tempat yang tidak semestinya.

Dengan demikian tidak mungkin dilakukan penjadwalan tanpa ada perubahan sistem pengelolaan angkutan umum yang memindahkan resiko finansial dari ditanggung pengemudi menjadi ditanggung perusahaan operator atau bahkan menjadi ditanggung pemerintah kota.

Tujuan dari studi ini adalah mengkaji bentuk pengelolaan sistem angkutan feeder agar rute, jadwal dan tarif dapat yang terdefinisi dan terinformasi dapat dibentuk dan berjalan dengan baik, serta mengkaji bentuk transisi dari sistem paratransit menjadi sistem transit dengan mempertimbangkan potensi dan keterbatasan sumber daya yang ada.

\section{Tujuan Studi}

Tujuan dari studi ini adalah mengkaji bentuk transisi dari sistem paratransit menjadi sistem transit dengan mempertimbangkan potensi dan keterbatasan sumber daya yang ada, untuk menciptakan kondisi pengelolaan sistem angkutan feeder dengan rute, jadwal dan tarif terdefinisi dan terinformasi dapat dibentuk dan berjalan dengan baik.

\section{Tinjauan Pustaka}

Surabaya dalam hal ini Dinas Perhubungan telah mempunyai rencana sintem angkutan umum yang melingkupi rute-rute angkutan umum berkelas semi rapid transit yang disebut Angkutan Massal Cepat (AMC), rute trunk dengan moda bus standard atau minibus, serta rute feeder dengan moda microbus disinggung pula tentang demand hingga rencana penjadwalannya, serta disebutkan pula tentang sistem buy the service [1]. Dijelaskan bahwa ada beberapa model struktur organisasi untuk terlaksananya

\footnotetext{
* Corresponding author. Tel.: +6281333258862; fax: +0315941490 .

E-mail address: wahjoesoeprapto@gmail.com
} 
buy the service tersebut secara garis besar. Dinas Perhubungan Surabaya juga mempunyai kajian integrasi yang menghitung besar demand dan struktur organisasinya [2].

Vuchic menjelaskan bahwa secara prisip sistem transit adalah rute, jadwal dan tarif fix, sedangkan bagaimana mengelolanya tidak disebutkan [3]. Gianopoulos menjabarkan tentang konsep jadwal yaitu headway minimum dan maksimum untuk bus kota [4]. Pengelolaan sistem layanan yang terkait dengan headway adalah penjadwalan dan informasinya, dimana time table merupakan pembulatan ke kelipatan 5 atau 10 menitan yang mudah diingat [5], atau berupa count down timer elektronik .

Pengelolaan pendapatan yang berupa berbagai sistem tiket juga merupakan hal yang penting dipertimbangkan [5]. Beberapa sistem tiket tidak cocok diterapkan ubtuk kawasan tertentu tergantung tingkat kedisiplinan masyarakatnya. Kebocoran pendapatan dari sistem tiket yang keliru akan berpengaruh terhadap kinerja sistem transit secara keseluruhan.

Pengelolaan operasional juga merupakan hal yang penting yang melibatkan susunan organisasi dari unsur pemerintah dan unsur operator, dan hubungan antara keduanya. Unsur operator dapat terdiri dari bermacam-macam unsur dengan segala kompleksitasnya [6].

Penjadwalan dan sistem informasinya dan beberapa sistem tiketing serta operasional sistem transit memerlukan infrastruktur pendukungnya. Yang dapat dikemukakan disini adalah halte dan depo serta terminal [3]. Pengelolaan infrastruktur ini juga perlu dilakukan pengelolaan yang tepat mengingat sangat mungkin akan dipergunakan bersama-sama oleh beberapa operator. Penilaian sistem transit yang terkait dengan feeder tidak mengambil inspirasi adalah Bus Rapid Transit Standard [7].

\section{Rencana Sistem Transit Surabaya}

Surabaya telah melakukan survey wawancara rumahtangga pada tahun 2011 guna mendapatkan besar demand yang dapat dilihat pada Gambar 1. Surabaya telah menyiapkan jaringan sistem transit terdiri dari 2 rute semi rapid transit, 15 rute bus trunk, dan 35 rute microbus feeder seperti dapat dilihat pada Gambar 1 pada tahun 2013.. Demand pada halte-halte juga dapat dilihat pada Gambar 3. Terdapat pula rencana pengelolaan yang dikemukakan seperti dapat dilihat pada Gambar 4 .

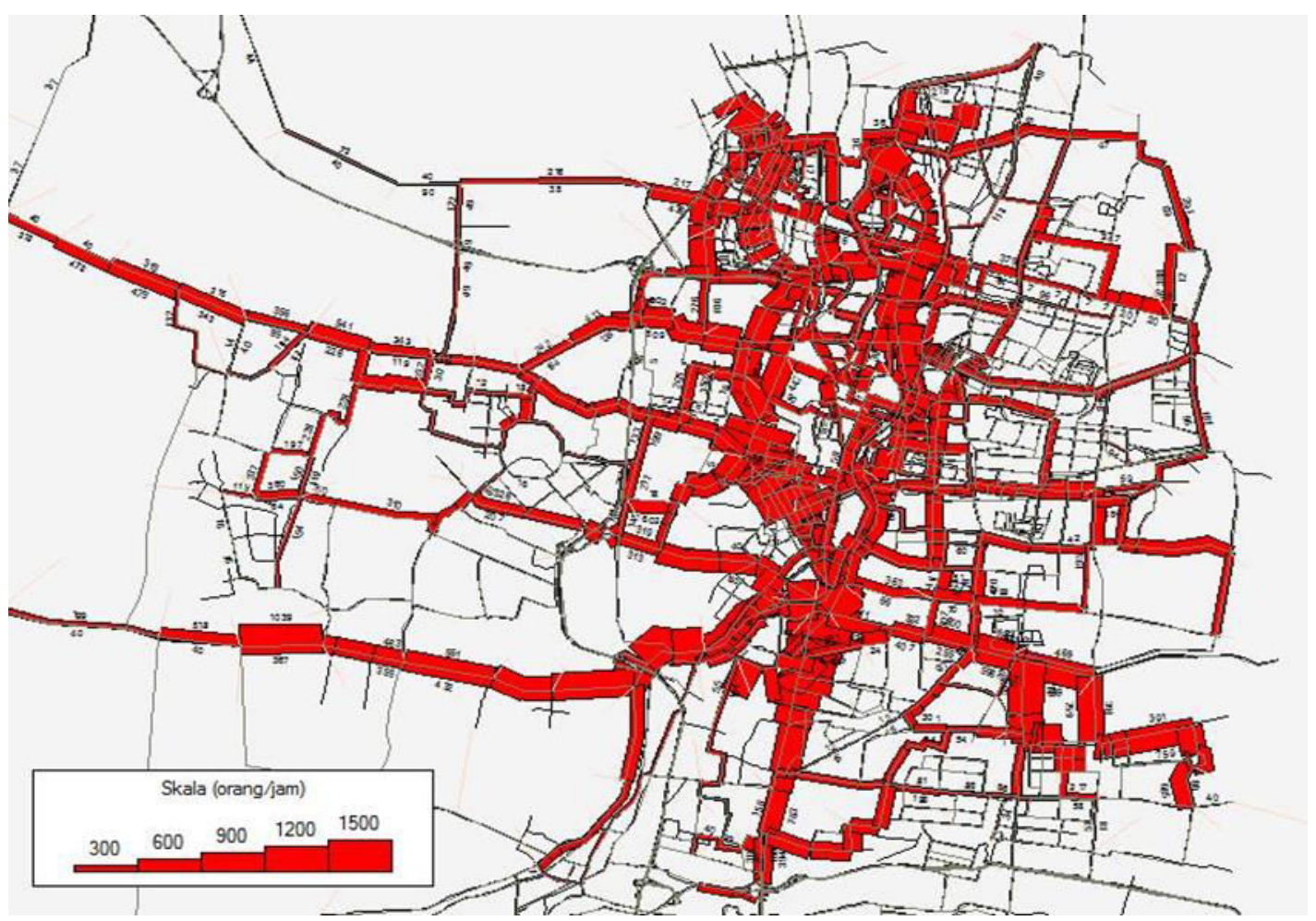

Gambar 1: Demand rencana hasil passenger assignment sebagai dasar rencana sistem transit 


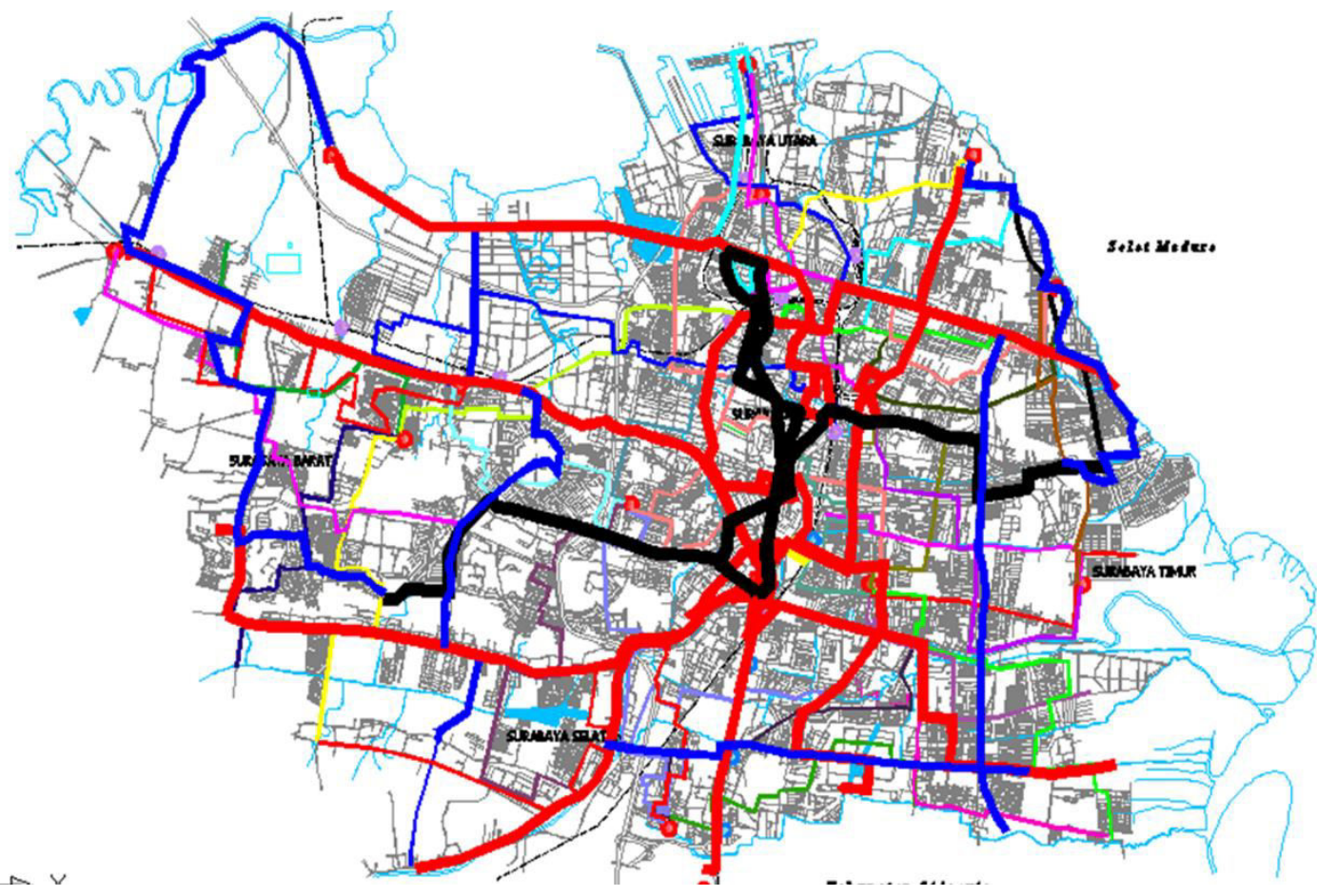

Gambar 2: Rute rencana sistem transit Surabaya terdiri dari semi rapid transit, trunk dan feeder

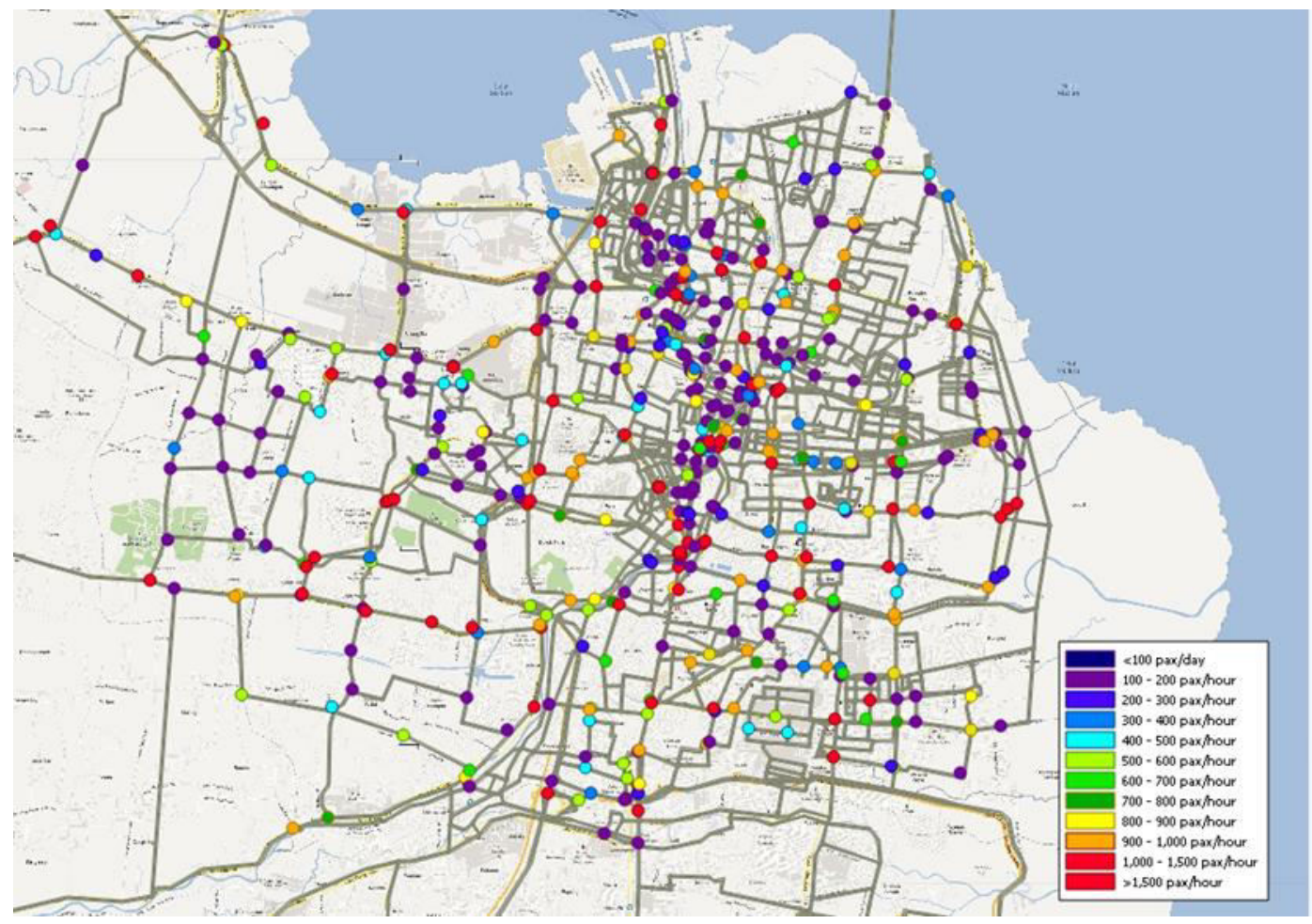

Gambar 3: Demand pada halte pada rute-rute sistem transit 


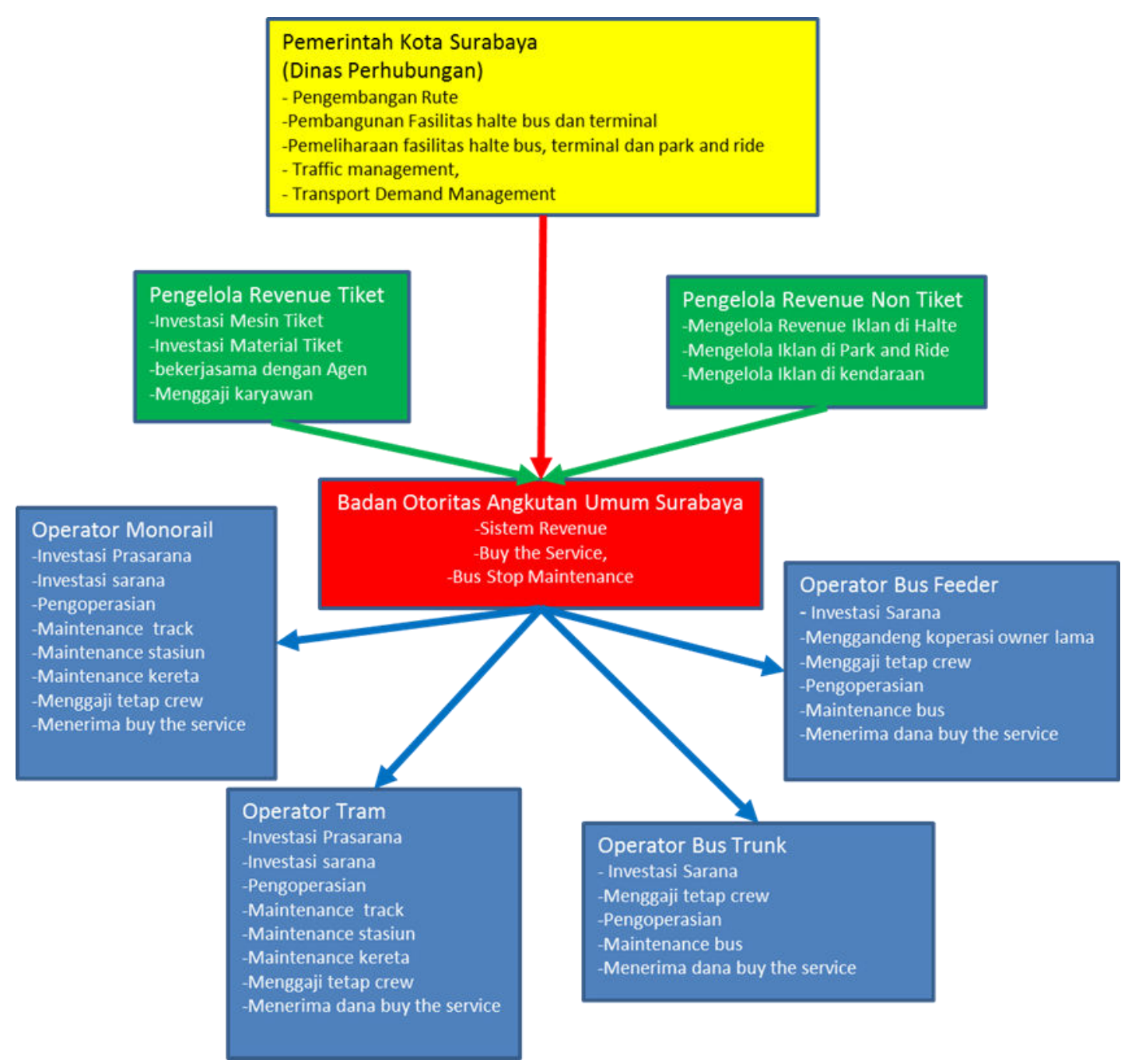

Gambar 4: Rekomendasi kelembagaan sistem transit Surabaya

Dapat dilihat bahwa Surabaya telah mempunyai rencana yang matang dalam studi demand, rencana jaringan transit hingga sistem kelembagaannya. Dalam studi ini akan dikemukakan beberapa alternatif sistem layanan, sistem operasional, sistem kepemilikan, dan sistem transisinya

\section{Beberapa Alternatif Pengelolaan Sistem Transit}

\subsection{Sistem layanan}

Beberapa alternatif pengelolaan sistem transit dapat dikemukakan dalam kaitannya dengan sistem layanan yang terkait dengan jadwal, yaitu:

- Jadwal diinformasikan dengan time table

- Jadwal diinformasikan melalui count down timer elektronik

- Jadwal diinformasikan melalui aplikasi handphone

Sistem transit lebih baik daripada sistem paratransit dengan ciri tidak terjadwal

\subsection{Sistem Pendapatan}

Beberapa alternatif pengelolaan sistem transit dapat dikemukakan dalam kaitannya dengan sistem pendapatan, yaitu:

- Pembayaran di kendaraan pada sopir atau kondektur dan diberi tiket

- Pembayaran di kendaraan pada mesin tiket

- Pembayaran sebelum masuk halte pada mesin tiket untuk membuka pintu halte

- Pembayaran jauh sebelumnya dan diberi kartu yang harus divalidkan di kendaraan / halte 
- Pembayaran jauh sebelumnya dan diberi kartu pintar yang harus ditab di halte/kendaraan/kondektur

Sistem transit lebih baik daripada sistem paratransit dengan ciri dibayar di kendaraan tanpa tiket atau dengan tiket. Tarif yang fixed hanya salah satu dari tiga unsur pembentuk sistem transit.

\subsection{Sistem Kontrak Operasional}

Operasional sistem transit dapat dilakukan dengan sistem kontrak berjangka waktu. Sistem kontrak dapat dilakukan dengan badan hukum, baik itu milik negara atau dengan swasta, bahkan dengan koperasi. Dalam kasus sistem transit feeder Surabaya dapat dilakukan kontrak dengan pemenang tender sebagai berikut:

- Satu operator berbadan hukum untuk satu kota

- Beberapa operator berbadan hukum dengan pembagian wilayah

- Banyak operator berbadan hukum dengan masing-masing melayani satu rute

Pada sistem paratransit tidak ada kontrak berjangka waktu, yang ada selama ini adalah pemerintah kota memberikan ijin tanpa perjanjian kinerja.

\subsection{Sistem Pengelolaan Kendaraan}

Dalam sistem transit, adanya jumlah kendaraan yang cukup akan menjamin keberhasilan penjadwalan. Kendaraan dapat diadakan dan dimiliki oleh operator maupun oleh pihak penyedia kendaraan. Kendaraan adalah aset berharga dalam jangka waktu kontrak. Beberapa sistem pengadaan dapat dilakukan sebagai berikut:

- Pemerintah kota mengadakan, memiliki dan memelihara kendaraan dan operator menyewa pada pemerintah kota

- Operator mengadakan, memiliki dan memelihara kendaraan sekaligus mengoperasikannya

- Perusahaan rental mengadakan, memiliki dan memelihara kendaraan dan operator menyewa pada pihak rental

Pada sistem paratransit kendaraan dimiliki oleh perorangan dan disewakan kepada sopir sedangkan ijin dipegang oleh pemilik. Sopir merupakan operator yang sebenarnya.

\subsection{Sistem Pengelolaan Fasilitas Pendukung}

Dalam sistem transit, halte merupakan fasilitas yang dapat dipergunakan untuk beberapa rute. Sedangkan depo atau pool merupakan fasilitas yang menjadi tanggung jawab dari pemilik kendaraan terkait dengan fasilitas pemeliharaan dan masalah keamanan (security). Beberapa model yang mungkin dapat diterapkan tentang halte adalah:

- Halte dibangun dan dikelola oleh pemerintah kota

- Halte dibangun dan dikelola oleh operator

- Halte dibangun dan dikelola oleh pihak ketiga

Berbeda dengan sistem transit yang mengharuskan adanya informasi kepada penumpang atau calon penumpang, sistem paratransit meniadakan keharusan tersebut. Dengan demikian sistem paratransit tidak memerlukan halte dengan konsekwensi kendaraan dapat berhenti di sebarang tempat.

\subsection{Terminal dan Depo}

Pada saat ini hampir semua rute paratransit berujung di terminal bukan sebagai tempat naik turun penumpang tetapi sebagai tempat parkir. Untuk sistem transit yang berjadwal yang terpenting adalah tempat turun naik penumpang berupa halte dan tempat parkir dan istirahat pengemudi berupa depo yang dapat berfungsi sebagai tempat pemeliharaan dan perbaikan. Variasi sistem transit dalam kaitan tersebut adalah:

- Tempat turun-naik dan transfer di halte dan terminal; parkir dan maintenance di depo

- Tempat turun-naik dan transfer di halte; tempat parkir dan maintenace di depo

Pada sistem paratransit selama ini tidak ada halte. Terninal ada tetapi terminal di pinggir kota berfungsi sebagai tempat parkir. Depo tidak ada karena mikrolet pulanf ke rumah pemilik di malam hari dan sebagian diparjir di tepi jalan. 


\section{Perbedaan Kondisi Existing Dengan Yang Diharapkan}

\subsection{Kondisi Eksisting}

Kondisi eksisting pengelolaan sistem paratransit di Surabaya adalah pemerintah memberi ijin kepada mikrolet secara perorangan, yaitu pemilik mikrolet yang mengajukan ijin apabila kuota untuk rute (lyn) masih dianggap mencukupi. Sementara itu sopir menyewa mikrolet harian dan mengoperasikannya untuk memperoleh uang ongkos dari penumpang.

Pada saat ini jumlah rute mikrolet sangat banyak yaitu 58 rute dengan bentuk rute tidak berpola mengikuti demand tetapi lebih berpatokan pada adanya terminal. Jumlah mikrolet hampir 5000 dengan jumlah aktif separuhnya. Setiap mikrolet disewa oleh seorang sopir dan msopir tersebut mempunyai sopir pengganti. Kapasitas mikrolet adalah 11 penumpang dengan tempat duduk bangku.

Biaya operasional ditanggung oleh sopir dan biaya maintenance ditanggung oleh pemilik. Apabila terjadi kecelakaan,perbaikan kecil ditanggung sopir dan perbaikan besar ditanggung pemilik. Pada umumnya ditad memiliki asuransi kendaraan. Penumpang membayar ongkos transportasi Rp 4000,- kepada sopir pada saat turun dari mikrolet.

\subsection{Kondisi Yang Diharapkan}

Kondisi yang diharapkan adalah rute mikrolet dipertimbangkan dengan dasar hasil studi demand (Gambar 1) dan terintegrasi dengan rute bus trunk dan rute semi rapid transit seperti pada Gambar 2. Moda yang akan dipergunakan adalah microbus dengan 15 penumpang dengan menggunakan kursi individual.

Penumpang hanya bisa naik-turun pada halte yang dilengkapi informasi. Penumpang diharapkan bisa pindah moda dengan mudah. Sistem tiketing diharapkan tidak mudah bocor dan murah.

Organisasi yang diharapkan adalah yang bisa mengintegrasikan beberapa moda sehingga perpindahan penumpang mudah. Organisasi juga memungkinkan sistem transit feeder mengikuti jadwal yang telah ditentukan sehingga organisasi yang diharapkan juga dapat membayar sopir dengan gaji tetap.

\subsection{Kriteria Masa Transisi}

Masa transisi merupakan peralihan dari kondisi masa kini yang bersistem paratransit menjadi kondisi yang diharapkan yang bersistem transit. Terdapat perbedaan-perbedaan menyolok yang harus dijembatani. Perbedaan-perbedaan tersebut dapat dilihat pada Tabel 1.

Tabel 1. Perbedaan kondisi eksisting dengan kondisi yang diharapkan

\begin{tabular}{|l|c|c|}
\hline & Kondisi Existing & Kondisi yang diharapkan \\
\hline Jumlah route & 58 & 35 \\
\hline Jumlah kendaraan & 4800 & Terjadwal \\
\hline Sistem penjadwalan & Tidak terjadwal & Badan Hukum \\
\hline Operator & Sopir & Tetap \\
\hline Penghasilan Sopir & Tidak Tetap & Halte dan terminal intermoda \\
\hline Naik-turun penumpang & Terminal dan sepanjang jalan & Badan Hukum \\
\hline Kepemilikan & Perseorangan & Ada \\
\hline Depo & Tidak ada & Ada \\
\hline Subsidi & Tidak ada & \\
\hline
\end{tabular}

Sangat penting untuk mengakomodasikan semaksimal mungkin pemilik dan sopir yang beroperasi saat ini, dimana hal ini akan memperkecil penolakan pada saat penerapan sistem baru.

\section{Proses Transisi}

Untuk mencapai kondisi yang diharapkan dengan perubahan berbasis kondisi eksisting, akan dikemukakan kesulitankesulatan yang harus dihadapi. Yang pertama adalah jumlah rute dari 58 tetapi tidak efektif dikurangi menjadi 35 rute. Hal ini memerlukan perombakan total dari rute saat ini yang dapat dilakukan serentak. Akan tetapi penciutan jumlah kendaraan dari 4800 menjadi 1500 akan mendapatkan tentangan dari pemilik mikrolet eksisting apabila pola kepemilikan tidak diubah. Maka 
dapat dilihat bahwa kepemilikan kendaraan oleh pemerintah maupun oleh operator (berbadan hukum) akan sangat mengurangi peran pemilik mikrolet existing, dimana hal ini dapat menimbulkan gejolak.

Solusinya adalah pemilik mikrolet lama diminta membentuk konsorsium (atau koperasi) per lyne dimana pada tahap I akan menerima uang sewa dari Badan Pelaksana Sementara Angkutan Feeder untuk sewa (pengganti setoran) mikrolet eksisting sementara sopir membentuk koperasi untuk mengoperasikan dengan kontrak dari Badan Pelaksana Sementara Angkutan Feeder, dan penumpang memasukkan uang ke box yang disegel milik Badan Pelaksana Sementara Angkutan Feeder.

Pada tahap kedua Badan Pelaksana Sementara mulai melakukan rerouting menjadi 35 rute sesuai hasil study. Pada tahap kedua itu konsorsium per lyne bergabung membentuk perusahaan rental microbus dengan skala jumlah yang lebih besar. Konsorsium rental tersebut mengadakan pembelian microbus feeder baru dan menawarkannya kepada pemilik lama untuk menanam saham dengan pembayaran tunai maupun barter dengan angkot lama. Angkot lama yang telah diserahkan kepada konsorsium bisa dijual kepadan umum atau kepada pemerintah untuk dijadikan asset publik misalnya untuk praktek otomotif sekolah kejuruan. Skema transisi dapat dilihat pada Gambar 4.



Gambar 5 : Skema Transisi Pengelolaan 
Pada saat rerouting menjadi 35 rute tersebut terjadi penysutan jumlah sopir dari 2x3500(yang beroperasi) menjadi 4x1500 akan terjadi kelebihan tenaga kerja sejumlah 1500 orang. Hal tersebut dapat diatasi dengan melatih sebagian menjadi pengemudi bus trunk karena jumlah bus sejumlah 600 bus akan membutuhkan tenaga kerja sopir 1800 orang atau kebutuhan sopir baru adalah 1300 orang. Sisanya sejumlah 1200 orang akan dilibatkan dalam penjualan tiket, cuci bus dan depo. Dengan demikian secara jumlah, tenaga kerja ex sopir tidak menjadi penganggur. Pada masa transisi halte bisa hanya berupa rambu yang dipasang di trotoar.

Setelah masa transisi Badan Pelaksana Sementara Angkutan Feeder akan digabungkan dengan Badan Pelaksana Transportasi yang bertugas menjadi regulator. Badan Pelaksana Transportasi ini akan mengadakan tender operator angkutan umum termasuk angkutan feeder sehingga dapat memilih beberapa badan usaha untuk mengoperasikan transportasi feeder di beberapa wilayah kota. Sistem tiket bisa mengaplikasikan smart card agar proses pindah moda lebih cepat. Pengawas dari Badan Pelaksana Transportasi menginspeksi penumpang secara insidentil. Halte sedikit demi sedikit dibangun berupa shelter dengan sistem informasi dan rambu. Rute yang baru dirancang tidak menggunakan terminal sehingga terminal mulai dialih fungsikan sebagai depo.

Yang paling kritis sebagai penghambat transformasi sistem angkutan mikrolet lama yang bersifat paratransit menjadi sistem transport feeder yang bersifat transit adalah sopir yang khawatir kehilangan pekerjaan, pemilik mikrolet yang khawatir kehilangan penghasilan, dan satu pihak lagi yaitu koordinator lyn microlet yang saat ini merupakan satu atau lebih orang kuat yang menarik uang sejumlah tertentu kepada pengemudi. Untuk pengelolaan masa depan pihak ini mungkin dapat direkruit ke dalam sistem pengawasan pada Badan Pelaksana Transportasi.

Keberhasilan untuk mentransformasikan sistem paratransit menjadi sistem transit sangat tergantung dengan kepastiankepastian kepada ketiga pihak ini dan memerlukan sosialisasi yang tak kenal lelah. Keberhasilan transformasi public transit merupakan point positif bagi kota-kota di Indonesia termasuk kota Surabaya, yang akan memudahkan masyarakat untuk melakukan aktivitasnya.

\section{Kesimpulan}

Transisi pengelolaan sangat penting dalam mengadopsi semua kepentingan para pihak yang selama ini telah berkecimpung dalam bisnis transportasim publik. Transisi yang krusial adalah dalam mengurangi jumlah kendaraan yang berimbas pada berkurangnya tenaga kerja sopir. Transisi tersebut meliputi pembentukan sistem kelemagaan yang berupa koperasi pemilik dan koperasi sopir mikrolet sejumlah lyn pada tahap pertama yang akan dikontrak oleh badan pelaksana sementara. Berikutnya masing=masing pihak akan membentuk badan usaha rental microbus feeder, badan usaha penyedia sopir, dan badan pelaksana transportasi. Halte akan bertransformasi dari tidak ada, pemasangan rambu saja, hingga terbangunnya shelter lengkap. Terminal akan difungsikan sebagai depo.

\section{Daftar Pustaka}

[1] Dinas Perhubungan Kota Surabaya, "Rencana Sistem Angkutan Umum," 2012.

[2] Dinas Perhubungan Kota Surabaya, "Studi Integrasi AMC, Trunk dan Feeder," 2014.

[3] V. R. Vuchic, Urban Transit System and Technology. John Willey \& Sons, 1981.

[4] G. A. Giannopoulos, Bus Planning and Operation in Urban Area: A Practical Guide. Gower Publishing, 1991.

[5] V. R. Vuchic, Urban Transit Operations, Planning and Economics. 2005.

[6] Ministry of Transport Singapore, "Why Bus Contracting," 2016.

[7] ITDP, “THE BRT STANDARD," 2014 